Max-Planck-Institut für demografische Forschung

Max Planck Institute for Demographic Research

Konrad-Zuse-Strasse 1 - D-18057 Rostock - GERMANY

Tel +49 (0) 3812081 - 0; Fax +49 (0) 3812081 - 202;

http://www.demogr.mpg.de

MPIDR WORKING PAPER WP 2003-011

APRIL 2003

The Past, Present

and Future of Demography

and the Role of the Max Planck

Institute for Demographic Research

Kenneth W. Wachter

This working paper has been approved for release by: Jan M. Hoem (hoem@ demogr.mpg.de)

Executive Director of the Max Planck Institute for Demographic Research.

(C) Copyright is held by the authors.

Working papers of the Max Planck Institute for Demographic Research receive only limited review.

Views or opinions expressed in working papers are attributable to the authors and do not necessarily reflect those of the Institute. 


\title{
The Past, Present and Future of Demography and the Role of the Max Planck Institute for Demographic Research
}

\author{
Kenneth W. Wachter
}

31 March 2003

I begin with a few lines from the most-cited of all demographic texts:

The days of our years are three-score years and ten, and if by reason of strength they be fourscore years, yet is their strength labour and sorrow.

So teach us to number our days, that we may apply our hearts unto wisdom.

These words from the Ninetieth Psalm, in King James' English translation of 1611, call to mind, by their contrast with present expectations, how deeply demographic change has now transformed the character of human life. They also remind us how ancient and encompassing are the issues being studied in this young Institute and within this new home for science whose opening we celebrate today. But I begin with these words for three more particular reasons:

1. The lines present a demographic estimate, an estimate of human lifespan fixed between 70 and 80 years, qualified by a measure of disability. This estimate turned out to be a successful prediction for longer than we who try to make predictions dare to hope.

2. The lines contain an injunction to do demography, moreover, to do quantitative demography:

"Teach us to number our days."

3. The lines reverberate with a conception of science that is integrated into emotion and purpose.

"Teach us to number our days, so that we may apply our hearts...." - not our heads, our hearts - "unto wisdom."

These three elements will be my leitmotiven as I speak briefly to the past, present, and future of demography, and the role of the Max Planck Institute for Demographic Research.

First, the past. I do not propose to look back with you over the heroic past of demography, the paradigmatic contributions of thinkers like Leonard Euler, John Graunt 
and/or Sir William Petty, Gregory King, David Hume, Johann Peter Süssmilch, Thomas Robert Malthus, Wilhelm Lexis, and Alfred Lotka. I only intend to dwell on the past of living memory - my living memory - on research that I have seen shaping the present horizons of demographic science. In particular, I call to mind three institutions which changed demography in the last century and which stand as precedents and exemplars for the Max Planck Institute today. I mean the Institut National d'Etudes Demographiques, the Cambridge Group for the History of Population and Social Structure, and the Office of Population Research at Princeton. Naturally, much of the important work in demography as in other fields is done by individuals scattered in diverse locations, and I can hardly touch on all of it. But in demography, a few centers have played a special role in the stimulation and sustenance of innovation, and this record of creative institutions forms the backdrop for our hopes for the Max Planck Institute.

To avoid invidious omissions forced on me by brevity, when discussing works of research I shall make it my practice in this talk to refer by name only to researchers who are no longer living.

I can only speak from limited personal experience about INED, the Institut National d'Etudes Demographiques, in its days on the Rue du Commandeur in Paris. Fortunately, Jacques Vallin will be speaking after me, and he may say more about the legacy of INED and its ramifications for Rostock. Beginning at INED in the decades following World War II, the conceptualization of contemporaneous demographic trends and transformations came to be guided by fundamental research in the seemingly specialized field of historical demography.

The concept of "natural fertility" developed at INED by Louis Henry represents an interesting step in intellectual history. Once upon a time the words "natural fertility" would have summoned up a highly biological concept. The human species like every other species would be assumed to have characteristic levels of offspring production and achievable lifespan, as indeed, in a very broad-brush picture, species do. Such a perspective is valid for distinguishing fireflies from finches and zebra from zebrafish.

The interest at INED was in working back with humans to a time in history when something like "natural" conditions set fertility levels without the intervention of conscious choice. Consciousness is not easily defined or measured, but Louis Henry's definition of "natural fertility" as fertility in the absence of what demographers call "parity specific control" gave an operational definition that could be applied directly to data. The new quantitative technique of family reconstitution opened up the exploitation of the information in long historical series of parish registers of births, marriages, and deaths. Then came the discovery - "natural fertility" was not simply "natural". Far from reflecting species-specific biological levels, fertility in the absence of decisiondriven human choice turned out to vary widely from society to society, time to time, and group to group. Social practices, environmental interactions, and institutional arrangements shaped the observable outcomes. 
The lines of research growing out of work at INED have put us in a position today to make fine distinctions on both sides of the divide labeled as conscious choice. Analysis focuses on the complementary roles of birth spacing and stopping behaviors, on the proximate determinants of fertility in the context of fertility reduction, and on the range of social and institutional factors that underlie much of the variation across the globe.

We might view our demographic concept of natural fertility, with its social and environmental emphases, as it developed first at INED, as a step away from or at least beyond biology. Today the Max Planck Institute can be seen to be closing a great circle, bringing demography back toward biology. The Max Planck Institute is the great center for biodemography, especially in studies of longevity. But the biology at issue now is not a biology of determinism and fixed distinctions. The emphasis is on plasticity and on an evolutionary heritage of flexible response.

I now turn to the Cambridge Group, to the charismatic figure of Peter Laslett, and to the theme of demographic myth. When we talk (and funders often like to hear us talk) of policy-relevant research, we are probably thinking of analyses weighing in on one or another side of some agency program or action, around decisions that will actually be made on utterly different grounds than the reasons we supply. But there is another kind of policy-relevant research. Demographers stand up with poets as "unacknowledged legislators of mankind". Our work slowly reshapes the myths and values about lifecourse and family that propel the long-term social agenda of societies.

One of the deepest myths about Western European society and its offshoots has been the myth of the extended, kin-connected, multi-generational family as a oncedominant and ideal form. In the years around the founding of the Cambridge Group in 1965, Peter Laslett set out to collect as many examples of listings of members of households in pre-industrial English villages as could be found. The listings were made sporadically, as he said, by "busybodies" - inspired busybodies, who put us in a position to see centuries later whether actual households and families reflected their presumed forms. What Peter Laslett and his coworkers discovered was a predominance of nuclear families. The rarity of non-nuclear families could not be explained away as an artifact of demographic constraints, as mathematical work showed. People must have been tending to live in nuclear families, then as now, because they chose to live in them. The extended kin-connected family as a dominant form was a myth.

Peter Laslett and his distinguished colleagues at the Cambridge Group went on to build on the foundation laid at INED to forge our present understanding of the demographic underpinnings and outgrowths of industrialization. They nurtured a host of researchers from England and around the world who took up the arduous tasks of village by village analysis. This work led to an understanding of the mechanisms regulating pre-industrial population growth. Patterns of adjustable late, companionate marriage specially characteristic of northwest European societies helped keep population growth from outrunning available resources. This system of homeostatic control 
functioned to protect the accumulation of economic surplus that made it possible to launch the first industrial take-off.

The separation of myth from reality in our notions of historical family structure led Peter Laslett and others to recognize continuities in our modern systems of social support and social insurance. The conceptual and mathematical treatment of homeostatic systems has been carried forward in time to model modern baby booms as well as backward to model prehistoric millenia.

Along with continuities, the Cambridge Group came to host emerging studies of the most visible discontinuity in social life. That is the extension of longevity beyond the psalmist's limit, and the emergence of a "Third Age" of active life beyond retirement and childrearing. This demographic transformation is seen to call for new institutions, new attitudes, and new kinds of life plans, as well as for systematic new research on future lifespan potential. Peter Laslett became a champion and supporter of the Max Planck Institute and its research initiatives, and he was very proud of this Institute. Peter is here in spirit today.

The Office of Population Research at Princeton University, the OPR, led by Ansley Coale and his distinguished associates, like the Cambridge Group, can be seen as facing up to myth. The Theory of the Demographic Transition took on dimensions of myth almost as soon as it began to circulate. In its basic form it portrayed processes of economic development and modernization as propelling a two-stage process, declines in mortality followed, with a lag, by declines in fertility, with temporary growth between. European transitions were to be a preview of world-wide transitions as economic development spread.

Ansley Coale wanted to isolate the particular indices of economic development that accounted for the European transitions. He launched the European Fertility Project, organizing studies country by country and developing new indices to take advantage of administrative data for small geographical areas. It turned out that European transitions fitted the basic theory poorly, much more poorly, in fact than later transitions in the developing world have turned out to do. The European "preview" turned out to be a play of its own, with a different plot and bigger roles for cultural factors, ideas, and the diffusion of innovations, than for the original stars of the economic development cast.

The most quoted lesson from the Princeton enterprise has been the salience of culture and institutional context in demographic change. But its largest contribution may well be the creation of a conceptual framework and a set of sensitive indicators of fertility change early enough that they could be brought to bear to guage and analyse the transitions that are now taking place in many parts of the world. The ideas and discoveries associated with OPR, like those associated with INED and with the Cambridge Group, were not confined to these locations. They emanated outward and enlisted the enthusiasm of demographers around the world. 
Now the Max Planck Institute for Demographic Research joins this honorable family of innovative institutions. Those of us who have been privileged to see the Institute in action have been impressed by the same qualities that have set the other centers apart. We feel the excitement of young people, breaking out from established routes, with fresh ideas and enthusiasms. Demography has gone through a very sparse period in this country, although it harks back to great work in earlier days. The young people here are not following established paths and pursuing conventional careers. Leaders in the revival of demography in Germany are gathered here today, and I am sure that they can tell us that it is an invigorating uphill struggle. Demography lies at the intersection point of the social, behavioral, and statistical sciences, and their health depends on the vitality of demographic research.

Demographers are obsesssed with tabulations by age and sex. The age pyramid of the Institute, like the age pyramid of the world, is broad at its base. The Institute pursues a strong commitment to gender balance. Constrained by laws governing employment, the Institute experiences heavy migratory flows, again like the world itself, and again like the world, the pace of migration poses challenges. Here the dynamics of generational renewal is more than an abstract object of study.

Like the other special institutes I have described, the Max Planck Institute reaches across disciplines. Sociology, economics, statistics, anthropology, mathematics, and history among other fields are represented in the pool of talent. The Institute is emphatically international, both in its resident research teams and in the great troupe of visitors from across Europe and the world who brave the journey to Rostock. INED, the Cambridge Group, and the Office of Population Research all exercised an influence far beyond their boundaries, through the individuals who gravitated to them and moved on with new research priorities, growing into leadership positions elsewhere. We see the Max Planck Institute embracing the same mission.

A further striking continuity between the other great centers and the Max Planck Institute is the pervasive presence of mathematics. The power of demography over the centuries and its pivotal role in the social sciences has come from its mathematical core. Demographic processes have proved to be more law-like than processes in almost any other human domain. Each of the great demographic institutes is known for a set of new measures and indices developed to take advantage of new sources of data, and the invention of indices has gone hand in hand with the articulation of underlying mathematical structures. The centrality of mathematics has been a founding principle of this Institute, especially appropriate for a social science institute within the larger Max Planck Society. I am not talking about mathematics for its own sake, but about mathematics as a guide to careful reasoning about the general patterns behind divergent instances. I am not going to be quoting equations in this talk, but I hope you have been having opportunities to enjoy mathematics over tea.

I have spoken a little about the past of demography, and I am now speaking about the present of demography. Creative science involves big questions grounded in painstak- 
ing detail. Demography today encompasses many more subjects and approaches than I can cover, around issues of population and development, fertility reduction in highfertility societies, the global burden of disease and epidemic, impacts on family structure, the environment, migration, transnationalism, ethnicity, intergenerational transfers, and intergenerational equity. Today I single out two big questions which seem to me to hold a place in the forefront of our attention.

These are questions of prediction, predictions that we as demographers urgently need to get right:

1. Will below-replacement fertility as we see it around us on this continent persist?

2. Will the pace of gains in longevity at older ages that we have seen in recent generations continue unabated for our children and our grandchildren?

In one guise or another, these two questions of prediction serve as focal points for much of the social, economic, political, statistical, and evolutionary thinking going in the profession of demography today. At the present time, these are mainly issues for the developed world, but it may not be very long before they impinge on the developing world as well.

In some respects, demographers have the best record of prediction among social scientists. Short and medium-term demographic projections form the reliable backbone for many fiscal and economic forecasts. But when we shift our scrutiny toward the long term and toward attempts to foresee great shifts and ground swells of change, the record is not so good. Demographers failed to predict the baby boom of the 1950s and 1960s in western nations. We failed to predict its abatement, what I prefer to call the "baby lull" rather than the "baby bust". We largely failed to predict the emergence of below-replacement fertility in Europe. We failed to predict that the slowdown in gains against mortality at older ages during the 1960s and 1970s would be followed by a resurgence of gains toward century's end. In short, the record is less than stirling. This time we want to get our predictions right.

The two questions of prediction that I have listed are of undisputed practical importance. They both loom large in the political decisions that have to be taken now, well in advance of crisis, to preserve the long-term viability of our national systems of social support and the social cohesion of our polities, under the assumption that stable, civilized life and progress as we have known it can be preserved in the face of the threats that now challenge it.

Persistence of below-replacement fertility has consequences for burdens of taxation, for the indigenous supply of labor, for family care for older people, likewise for relieving pressure on the environment, and for the intensity of investments in the young. Continuing extensions of longevity have consequences for institutions and the 
economy, for politicians, whose fiscal estimates of social insurance and medical costs may already be obsolete, and for all of us making lifetime plans.

These things we all know. The important point is that strains can be minimized and opportunities maximized if our adaptations are gradual and informed by valid foresight. Successful demographic prediction now could alter the balance of wellbeing over the lifetimes of the people in this room.

Our two questions of prediction are, then, central challenges for present-day demography. They are also rallying-points for the laboratories of the Max Planck Institute.

The Laboratory of Fertility and Family Dynamics, under the leadership of Jan Hoem, has taken up a broad range of empirical investigations that bear on the long-term persistence of below-replacement fertility. A key element is the recognition that the different nations and regions of Europe provide a set of natural experiments. Substantial variation exists in government policies and institutions, in economic experience, in cultural and social norms and practices, and in the timing of changes. Alongside the common overall trends, a patchwork of differences can be seen in detailed outcomes of interest, rates of progression into childbearing, ages and types of union formation, kin sets, coresidence, and lifestage transitions. This variability of determinants and outcomes offers the opportunity in principle to sort out the competing paths of influence.

The prerequisite for such analysis is getting the facts right. For that enterprise, the Max Planck Institute is uniquely situated, both in location and in its mix of personpower, between north and south, between east and west, between boom and struggle.

The research program stretches across country studies, case studies, and synthetic studies. In a case study comparison of Sweden and Norway, the Laboratory has produced the cleanest case I know for a direct influence of a change in democratic government policy on realized rates of first birth. Work here has built a framework for analyzing panel data on the component processes, of transition out of childhood into adulthood, which no longer follow each other in a traditional standard order. Rostock research has highlighted the demographic impact of household change on energy use and environmental stress. Other work has generated a prototype model grounded in mathematics and economics incorporating effects of peer pressure and social learning on childbearing by birth order. This model has what are called tipping points, dynamic instabilities in which small differences may be amplified into substantial contrasts in fertility outcomes.

Dominating thinking about the origins of low fertility are the changing roles, goals, and opportunities for women and hypotheses about the irreversibility of their implications for fertility. Speculation is easier than empirical validation. The Max Planck Institute is joining an ambitious multi-center and multi-country program coordinated by the Economic Commission of Europe to collect new survey data comparable across 
countries on the subject of "Gender and Generations". The data will include retrospective life histories, attitudes, and expectations, and a longitudinal component which may make causal analysis feasible, and carry us closer to consensus on the prospects for the persistence of below-replacement fertility.

The Laboratory of Survival and Longevity, under the leadership of Jim Vaupel, has pioneered a domain of basic research bearing directly on the question of the continuance of the current pace of progress against mortality at older ages. Rostock is a center for the new field of "Biodemography". Most official forecasts of mortality incorporate assumptions of diminishing returns to future efforts at life extension. Part of the justification for these assumptions comes from a belief in built-in constraints on lifespans, built in by the operation of very general principles of Darwinian natural selection that apply to other organisms and to humans as well. The classic evolutionary theory of senescence developed over the last half-century by geneticists and biologists has seemed to offer support to beliefs in tight constraints.

Today, that line of argument is in doubt, thanks to empirical discoveries in biodemography by members of the Max Planck Institute and their colleagues in other centers. Studies of large populations of model organisms including species of flies and worms have found graphs of mortality rates as functions of age that stop rising ever more steeply with age and actually bend over at extreme ages, contrary to theoretical expectations. The careful assembly and verification of data on human survival to extreme ages coordinated from Rostock have established that human mortality rates also stop rising with age at extreme ages and may actually bend down. These discoveries have stimulated world-wide efforts to design and analyze new mathematical models which can help to reconcile ideas from the evolutionary theory of senescence with the newly observed patterns of age-specific variation. The Max Planck Institute has taken the lead in models for persistent heterogeneity in frailty. New statistical approaches applied to data from the Danish twin registry have given us our best estimates of heritability for frailty and lifespan.

The focus in this domain of demography is on gradual and widely diffused extensions of lifespan of the kind we have seen over the last century. We are not engaged in estimating probabilities for breakthroughs in bio-engineering or the conquest of aging. What has been remarkable about the past is the steady pace of progress, reflected, for example, in a longstanding linear upward trend in life expectancy in the country leading the world in life expectancy, a regularity recently uncovered here at the Max Planck Institute. Such regularities argue for a deeply rooted structure of biological opportunity overriding the off-again, on-again interventions of particular breakthroughs, and amenable to demographic research.

Shall we say to our grandchildren, "The days of your years are four-score years and ten"? And if, by reason of strength, they be six-score years, will their strength be labour and sorrow, or will it be clarity and closure? What will we be saying to greatgrandchildren? What great-grandchildren in what numbers will be there to whom to 
speak?

There are many technical steps and small details that have to come together slowly, systematically and serendipitously, to give us credible answers to big questions like the issues of prediction facing demographers today. The questions are important in their own right, but they are also important because they make us branch out into the study of so many aspects of life as it is lived. The elements of demographic study are the fabric of experience, bonding, parenting, maturing, parting, the currency of privilege and deprivation, frustration and fulfillment.

I have been talking about the past and the present of demography, and I am going to let what I have said about the past and present stand in for the future. For my fiftieth birthday, a friend sent me two lines from the poet Robert Frost:

I went to school to age to learn the past...

I go to school to youth to learn the future.

You have been listening to me about the past, but to learn about the future of demography, you should go out into the corridors and what will be the gardens of this beautiful new building, and talk to the young scientists who are making the future here.

I would like to conclude with a few words in the other language of this Institute:

Hier sind meine Wünsche:

Im neuen Hause werde die Demographie als Naturwissenschaft gepflegt. Wenn sich Mathematik mit Leidenschaft verbindet, ist und bleibt die Summe groß.

Das Institut ist freilich weltumfassend, international. Laßt uns auch seine hanseatische, seine mecklenburgische, seine deutsche Herkunft preisen, wie Hölderlin uns mahnt:

"Denn wie die Pflanze, wurzelt auf eigenem Grund sie nicht, verglüht die Seele des Sterblichen".

Ob das Max-Planck-Institut wohl den Namen vom Theoretiker des Schwarzkörpers trägt, möge es vielmehr die hohe Tradition der Farbenlehre fortsetzen, die Verwandtheit alles Lebendigen erklären, unsere Tage zählen, unsere Herzen auf die Weisheit richten.

"Soll das Werk die Meister loben. Doch der Segen kommt von oben".

Quellen: Robert Frost, "What Fifty Said"

Friedrich Hölderin "Mein Eigentum"

Friedrich Schiller "Das Lied von der Glocke" 